\title{
Do agreeableness and neuroticism explain age differences in the tendency to forgive others?
}

\author{
Steiner, Marianne ; Allemand, Mathias ; McCullough, Michael E
}

\begin{abstract}
Previous research has shown that age is positively related to a dispositional tendency to forgive others. The present investigation tested the hypothesis that agreeableness and neuroticism partially mediate the association between age and forgivingness. Data from two representative cross-sectional samples of adults were used to test this hypothesis. Results from Study 1 ( $\mathrm{N}=962$, age range: 1984 years) support the hypothesis, indicating that agreeableness and neuroticism explained, in part, age differences in tendencies to forgive. Study $2(\mathrm{~N}=451$, age range: $20-83$ years) replicated and extended the results by including transgression occurrences as a third mediator. The results showed that agreeableness and neuroticism explain the association between age and the tendency to forgive others over and above the effect of transgression occurrences.
\end{abstract}

DOI: https://doi.org/10.1177/0146167211427923

Posted at the Zurich Open Repository and Archive, University of Zurich ZORA URL: https://doi.org/10.5167/uzh-69022

Journal Article

Originally published at:

Steiner, Marianne; Allemand, Mathias; McCullough, Michael E (2012). Do agreeableness and neuroticism explain age differences in the tendency to forgive others? Personality and Social Psychology Bulletin, 38(4):441-53.

DOI: https://doi.org/10.1177/0146167211427923 
Running Head: EXPLAINING AGE DIFFERENCES IN FORGIVINGNESS

Do Agreeableness and Neuroticism Explain Age Differences in the Tendency to Forgive Others?

\author{
Marianne Steiner \& Mathias Allemand \\ University of Zurich
}

\author{
Michael E. McCullough \\ University of Miami
}

Corresponding author:

Mathias Allemand

University of Zurich

Department of Psychology

Binzmühlestrasse 14/24

CH-8050 Zurich

Switzerland

Phone: +41 446357415

E-mail:m.allemand@psychologie.uzh.ch 


\begin{abstract}
Previous research has shown that age is positively related to a dispositional tendency to forgive others. The present investigation tested the hypothesis that agreeableness and neuroticism partially mediate the association between age and forgivingness. Data from two representative cross-sectional samples of adults were used to test this hypothesis. Results from Study 1 ( $N=962$, age range: 19 to 84 years) support the hypothesis, indicating that agreeableness and neuroticism explained, in part, age differences in tendencies to forgive. Study 2 ( $N=451$, age range: 20 to 83 years) replicated and extended the results by including transgression occurrences as a third mediator. The results showed that agreeableness and neuroticism explain the association between age and the tendency to forgive others over and above the effect of transgression occurrences.
\end{abstract}

KEYWORDS: forgivingness; personality traits; agreeableness; neuroticism; adulthood; age differences 


\section{Introduction}

Theory and research suggest the existence of age differences in forgivingness, defined as individual differences in the tendency to forgive others that is at least consistent across relationships and transgressions (Allemand \& Steiner, 2010, in press). Older adults are, on average, more willing to forgive others than middle-aged and younger adults, and children and adolescents are least willing to forgive others (Allemand, 2008; Enright, Gassin, \& Wu, 1992; Girard \& Mullet, 1997; Hill \& Allemand, 2010; Krause \& Ellison, 2003; Mullet \& Girard, 2000; Mullet, Houdbine, Laumonier, \& Girard, 1998; Steiner, Allemand, \& McCullough, in press). For example, Subkoviak et al. (1995) found college students to be less willing to forgive others than their middle-aged parents. In an U.S. probability sample, Toussaint, Williams, Musick, and Everson (2001) reported middle-aged (45-64 years) and older adults (65 years and older) being more willing to forgive others as compared to a younger age group (18-44 years). Moreover, Lawler-Row and Piferi (2006) found age differences in forgivingness in a study of adults ranging in age from 50 to 95 years, with older adults describing themselves as being more forgiving than the middle-aged adults.

As research continues to show age differences in forgivingness, it also raises questions about the psychological processes that are responsible for these differences. To date, there are a few theoretical accounts for explaining age differences in forgivingness. Most of these explanations invoke either person-related factors such as beliefs and values or context-related factors such as life events (for reviews, see Allemand \& Steiner, 2010, in press). However, few studies have empirically tested potential psychological explanations for age differences in forgivingness. For example, older adults may have certain beliefs or value systems that predispose them to be more forgiving than younger adults (Romero \& Mitchell, 2008). Indeed, previous research has shown that age is positively associated with religiousness (Idler, 2006), and religiousness, in turn, with forgivingness (Mullet et al., 2003). Older adults also might have different goal preferences in the social domain than younger adults, as has been 
suggested by socio-emotional selectivity theorists (Carstensen, Isaacowitz, \& Charles, 1999). The theory assumes that the regulation of emotions receives greater priority as people age because chronological age is negatively associated with time left in life. Hence, forgivingness might become a useful resource and strategy as people pass through older adulthood (Bono \& McCullough, 2004). Allemand (2008) and Cheng and Yim (2008) tested this hypothesis empirically and demonstrated that the effect of future time perspective explains, in part, age differences in forgivingness.

Another possible explanation for age differences in forgivingness is the past time perspective (cf. Allemand, 2008). This perspective assumes that aging is related to a greater number of life experiences and, consequently, more knowledge and judgment about life and ways of planning, managing, and understanding life (Baltes, Lindenberger, \& Staudinger, 2006). The association between aging and forgivingness thus might be due to an effect of increased experiences with interpersonal problems, transgressions, and forgiveness across the adult lifespan. With increasing age individuals might gain more expertise in letting go of hurtful feelings and thoughts, and therefore be more inclined to forgive others than middleaged and younger adults. Furthermore, transgression occurrences might vary across the lifespan as a consequence of being exposed to different social contexts and roles. Recently, Steiner et al. (in press) tested this hypothesis cross-sectionally and found that older adults experience interpersonal transgressions less frequently than do younger adults, and that they also perceive the transgressions that do occur to them as less intense. Moreover, those age differences in transgression occurrences explain, in part, why older adults are more willing to forgive.

The major goal of the present investigation, therefore, was to extend previous research by clarifying the role of agreeableness and neuroticism for age differences in forgivingness. We tested the hypothesis that agreeableness and neuroticism partially mediate the association between age and forgivingness. The theoretical rationale for the mediation hypothesis is based 
on the hierarchy of breadth of constructs such as traits (e.g., Roberts \& Pomerantz, 2004) or affect (e.g., Rosenberg, 1998). Agreeableness and neuroticism are broad and global traits that can be displayed on an ongoing and steady basis across different situations (cf. Funder, 1991), whereas forgivingness is usually displayed according to the demands of specifiable situations such as interpersonal conflicts. The tendency to forgive others is only relevant in social settings that call for it. Put differently, forgivingness is a narrower and more context-specific situational trait in contrast to the broader and more inclusive global traits agreeableness and neuroticism. Although the opportunity clearly exists for bidirectional associations among global and situational traits, in the mediation hypothesis we consider here, we assume that the direction of influence primarily follows the pattern of flow from broad traits to more contextspecific traits. Therefore we investigated agreeableness and neuroticism as antecedents of forgivingness.

The hypothesis of the present investigation was motivated by two arguments. First, cross-sectional and longitudinal research suggest age differences and age-related changes in agreeableness and neuroticism across the lifespan (Allemand, Zimprich, \& Hendriks, 2008; Allemand, Zimprich, \& Martin, 2008; Donnellan \& Lucas, 2008; Roberts, Wood, \& Caspi, 2008; Srivastava, John, Gosling, \& Potter, 2003; Terracciano, McCrae, Brant, \& Costa, 2005). For example, in a very large cross-sectional sample of Internet users aged 10 to 65 ( $N$ $=1,267,218)$, Soto, John, Gosling, and Potter (2011) recently demonstrated that agreeableness tends to increase in adulthood, whereas neuroticism tends to decrease with age. Furthermore, in a comprehensive meta-analytic review of longitudinal studies, Roberts, Walton, and Viechtbauer (2006) found similar positive age trends for agreeableness and negative age trends for neuroticism across adulthood.

Several explanations exist for these age differences. In general, age differences in agreeableness and neuroticism can be attributable to social and/or biological factors (McCrae et al., 2000; Roberts et al., 2008). For example, the maturity principle assumes that people 
tend to gain on those traits that help them to adjust to adulthood (Roberts \& Wood, 2006).

More specifically, people tend to become socially more dominant, agreeable, conscientious, and emotionally stable with age. Higher levels of agreeableness and lower levels of neuroticism are qualities that facilitate social functioning in interpersonal relationships, social groups, and in society in general (Roberts et al., 2008). In addition, the social investment principle supposes that investing in social institutions, such as age-graded social roles, is a key mechanism for personality development (Lodi-Smith \& Roberts, 2007). The idea is that social roles in different domains such as work, marriage, family, and community roles contain cultural, societal, and individuals' expectations how to behave in the roles, and that an active, psychological investment to the roles might lead to personality development in general and to greater maturity in particular.

Second, agreeableness and neuroticism are not only related to age, but also to forgivingness. Research has consistently demonstrated that these two traits are correlates of the tendency to forgive (Allemand, Job, Christen, \& Keller, 2008; Ashton, Paunonen, Helmes, \& Jackson, 1998; Berry, Worthington, Parrott, O’Connor, \& Wade, 2001; Brown, 2003; McCullough, Bellah, Kilpatrick, \& Johnson, 2001; McCullough \& Hoyt, 2002). For example, using a scenario-based measure of forgivingness Berry et al. (2001) found moderate positive correlations between forgivingness and agreeableness, and moderate negative correlations between forgivingness and neuroticism. Furthermore, in a multi-sample study Berry, Worthington, O’Connor Parrott, and Wade (2005) replicated the results and even found stronger associations with agreeableness and neuroticism. In a recent meta-analysis, Fehr, Gelfand, and Nag (2010) found similar associations between forgiveness of a single transgressor by a single victim and agreeableness $(r=.22)$ and neuroticism $(r=-.24)$. Finally, previous research also demonstrated predictive effects of personality traits on forgiveness. For example, Maltby et al. (2008) have demonstrated that neuroticism, and specifically anger hostility, prospectively predict forgiveness two and a half years later. 
Several explanations exist for these consistent patterns of associations with forgivingness. Agreeableness represents an interpersonal personality trait that contrasts a prosocial and communal orientation toward others with antagonism. It refers to individual differences in the tendency to be altruistic, trusting, modest and warm (John, Naumann, \& Soto, 2008; John \& Srivastava, 1999). Individuals who score high in agreeableness tend to have less conflict in relationships than less agreeable people (Asendorpf \& Wilpers, 1998). Agreeable individuals are also better able to regulate their emotions during interpersonal interactions, which facilitate smoother interpersonal encounters (Tobin, Graziano, Vanman, \& Tassinary, 2000). Agreeableness is also related to interpersonal features that are helpful in interpersonal interactions such as empathy and perspective taking (Ashton et al., 1998; Mullet, Neto, \& Rivière, 2005).

Neuroticism represents an intrapersonal personality trait that contrasts emotional stability and even-temperedness with negative emotionality such as feelings of anxiety, worry, anger, and depression (John et al., 2008; John \& Srivastava, 1999). Individuals who score high on neuroticism tend to have a lower threshold for experiencing negative affect and they marshal more attention toward negative stimuli than do people low in neuroticism (Derryberry \& Reed, 1994). Consistent with the negative association to neuroticism, forgivingness is negatively related to other intrapersonal features comprising neurotic elements, e.g., state and trait anger, anxiety, depression, negative affectivity, and rumination (McCullough et al., 2001; Mullet et al., 2005).

\section{The Present Investigation}

The present investigation, which involved the collection and analysis of two crosssectional data sets, had two objectives: The first objective was to extend previous research on age differences in forgivingness by testing the hypothesis that agreeableness and neuroticism partially mediate the association between age and forgivingness. In Study 1 we used a large age-stratified, randomly selected representative sample to test this hypothesis. Such a 
sampling technique provides generalizability allowing for robust evidence regarding the patterns of associations between age, agreeableness, neuroticism, and forgivingness. The mediation analysis is based on the assumption that forgivingness is related to but is distinct from agreeableness and neuroticism, respectively — an assumption that, if untested, could lead to imprecise estimations of the associations. Therefore, we first aimed to demonstrate the discriminant validity of forgivingness with respect to agreeableness and neuroticism before testing the mediation hypothesis.

The second objective was to replicate and to extend the results from Study 1. In our previous cross-sectional work we have found that older adults experience transgressions less frequently and less intensely than middle-aged and younger adults. Furthermore, we have demonstrated that transgression occurrences partially explain the association between age and forgivingness (Steiner et al., in press). Therefore, in Study 2, we tested the mediation hypothesis simultaneously for agreeableness, neuroticism, and transgression occurrences as mediators to investigate the comparative validity of the different theoretical accounts. The main purpose was to explain whether agreeableness and neuroticism additionally explain the association between age and forgivingness over and above the mediating effect of transgression occurrences.

\section{Study 1}

\section{Participants}

Nine hundred sixty-two participants $(57.3 \%$ women) ranging in age from 19 to $84(M=$ 52.4 years, $S D=17.7$ ) participated in a large-scale survey. With respect to educational attainment, $7.0 \%$ reported having a basic education as the highest level of education, $39.7 \%$ reported attending school education or equivalent, $24.4 \%$ completed a degree from a technical school, and $28.9 \%$ attended university degree. Regarding marital status, 35.3\% participants were single, $45.8 \%$ were married, $12.5 \%$ were either separated or divorced, and $6.5 \%$ were widowed. 


\section{Sampling Procedure}

The sampling procedure involved an age-stratified random selection of prospective study participants accomplished by the registration office of the city of Zurich, a city in Switzerland with about 380,000 inhabitants. Zurich is located in the German linguistic and cultural region of Switzerland. From each birth-year age group (1929 to 1989), we included 66 adults with an approximately equal ratio of men and women, resulting in 4,026 prospective German-speaking participants. To avoid problems due to lack of linguistic skills the random selection only included German-speaking persons. This sampling procedure was successfully used in previous studies (e.g., Zimprich et al., 2008).

Prospective study participants received a package consisting of a personalized letter including a description of the study and its required time commitment, information about protection of data privacy, a sociodemographic questionnaire, the study materials including several questionnaires, and a postage-paid business reply envelope for mailing the material back to the researchers. Parts of the questionnaire of the large-scale survey were items on forgivingness, agreeableness, and neuroticism. Due to protection of privacy the procedure included the deletion of all postal addresses after sending the package to prospective participants. Consequently, we were not able to remind participants to fill out the questionnaire. In light of this fact the response rate of $24 \%$ is notable. All participants were unpaid volunteers.

To determine the degree of sample selectivity, we compared the initial sample of prospective participants $(N=4,026)$ with the final sample $(N=962)$ with respect to age and gender, as we only have information about age and gender of prospective participants. The mean age in the final sample $(M=52.4, S D=17.6)$ was slightly higher than in the entire sample. In terms of effect sizes this difference is small, $d=.14$. Slightly more women $(56.9 \%)$ participated in the study as compared to the sample of all prospective participants $(51.3 \%)$.

\section{Measures}


Forgivingness. The Tendency to Forgive Scale (TTF; Brown, 2003) was used to assess individual differences in forgivingness. Example items are "I tend to get over it quickly when someone hurts my feelings," and "When people wrong me, my approach is just to forgive and forget." Each of the four items was followed by a 7-point Likert-type scale anchored with strongly disagree (1) and strongly agree (7). The alpha reliability estimate for the TTF was .68. Several studies provided support for the TTF being a reliable and valid instrument that also demonstrated favorable self-informant correlations. Moreover, TTF is related to several individual and social outcomes, such as higher levels of perspective taking and positive social relations, and lower levels of depression and negative affect (Brown, 2003; Brown \& Phillips, 2005; Hill \& Allemand, 2010).

Agreeableness and neuroticism. The Agreeableness and Neuroticism scales from the Big Five Inventory (BFI; John, Donahue, \& Kentle, 1991; Rammstedt \& John, 2005) were used to assess individual differences in the two personality traits. Each item of ten agreeableness items and the eight neuroticism items was followed by a 5-point Likert-type scale with responses ranging from disagree strongly (1) to agree strongly (5). We excluded one agreeableness item ("I see myself as someone who has a forgiving nature") to avoid item overlap with our forgivingness measures. Alpha reliability estimates for the two scales were: Agreeableness: $\alpha=.69$, Neuroticism: $\alpha=.83$. The BFI is widely used and well validated (John et al., 2008).

\section{Statistical Analyses}

We used latent variable mediation analyses by means of structural equation models (SEM) to test our mediation hypothesis (cf. MacKinnon, 2008). We performed the analyses in two steps, whereby the first step reflected preliminary analyses for the meditation analyses. First, we estimated a measurement model for the latent construct forgivingness using the four items of the forgivingness measure as manifest indictors. We then examined the association between latent forgivingness and age. Next, we estimated a model with the two latent 
personality constructs agreeableness and neuroticism and also examined the association with age. For the two personality traits we used three parcels as manifest indicators per trait rather than single items. Parcels were built by averaging several items according to the item-toconstruct balance technique (Little, Cunningham, Shahar, \& Widaman, 2002, p. 166). To demonstrate that forgivingness is related to but is distinct from agreeableness and neuroticism, respectively, we compared two-factor models with single-factor models. For example, if forgivingness is distinct from the two constructs, then it should be necessary to specify two unique but correlated factors to account for the covariances among the indicators of the forgivingness measure and any of the other scales. In such a case, a two-factor model specifying that the indicators loaded on distinct but correlated latent variables would fit better than a single-factor model comprising of all indicators. Eventually, we estimated a measurement model that includes all three latent constructs. This model exhibits the starting point for the subsequent mediation analyses.

Second, to test the mediation hypothesis we set up a structural mediation model consisting of one independent manifest variable (age), two latent variable mediators (agreeableness and neuroticism), and one latent outcome variable (forgivingness). In this type of mediation model, there are five direct effects: age $\rightarrow$ forgivingness, age $\rightarrow$ agreeableness, agreeableness $\rightarrow$ forgivingness, age $\rightarrow$ neuroticism, and neuroticism $\rightarrow$ forgivingness; two specific indirect (mediating) effects: age $\rightarrow$ agreeableness $\rightarrow$ forgivingness, age $\rightarrow$ neuroticism $\rightarrow$ forgivingness; and a total effect and a total indirect effect. All direct effects were tested by means of the $z$-statistic. The indirect effects were tested using bootstrapping (Preacher \& Hayes, 2008). Simulation research has shown that bootstrapping is one of the more valid and powerful methods for testing indirect effects as it has relatively high power while also maintaining reasonable control over the Type I error rate (MacKinnon, Lockwood, Hoffman, West, \& Sheets, 2002; Williams \& MacKinnon, 2008). Tests of indirect effects were performed using 5,000 bootstrapped samples and we report asymmetric percentile 
bootstrap 95\% confidence intervals (CI). An effect is statistically significant if its confidence interval does not include zero. Because previous studies have reported gender effects in forgivingness (Miller, Worthington, \& McDaniel, 2008; but see Fehr et al., 2010) we controlled for gender in all mediation analyses.

All analyses were performed using maximum likelihood estimation in Mplus version 5.0. To assess goodness of fit of the models, we examined the chi-square $\left(\chi^{2}\right)$, comparative fit index (CFI), standardized root-mean-square residual (SRMR), and root mean square error of approximation (RMSEA) statistics. Hu and Bentler (1998) noted that SRMR is less sensitive to distribution and sample size, and recommended its use in combination with CFI when using maximum-likelihood (ML) estimation. CFI values greater than .95, SRMR values less than .05 , and RMSEA values less than .06 are typically considered to indicate that a SEM model is adequately parameterized, although values as low as .90 and as high as .10, respectively, are acceptable (Browne \& Cudeck, 1993; Hu \& Bentler, 1998). Model comparisons were performed using nested chi-square $\left(\Delta \chi^{2}\right)$ tests.

\section{Results and Discussion}

\section{Preliminary Analyses}

Means, standard deviations, and correlations among study variables appear in Table 1. First, we estimated a series of preliminary measurement models as specified in the statistical analyses section. Each model was identified by the marker variable method. In this case, the loading and intercept of one of the indicators of the three latent constructs are fixed to be one and zero, respectively. The measurement model for forgivingness did not achieve an acceptable fit, $\chi^{2}(2)=44.49, p<.01, \mathrm{CFI}=.930, \mathrm{SRMR}=.048, \mathrm{RMSEA}=.150$. The $\chi^{2}-$ value, however, is almost always significant in large samples. Inspection of the modification indices indicated a large residual covariance between the two reverse coded items 2 and 3. Thus, the residual covariance between the two items was freely estimated. Doing so improved the model fit considerably, $\chi^{2}(1)=0.60, p=.44, \mathrm{CFI}=1.000, \mathrm{SRMR}=.005, \mathrm{RMSEA}=.000$. 
We therefore decided that this forgivingness model adequately describes the data. Age was positively related with latent forgivingness, $\beta=.27, p<.01$. This finding is consistent with previous research and implies that participants become more willing to forgive others with increasing age. We also tested for a curvilinear relationship between age and forgivingness. Age-squared was virtually unrelated to forgivingness, $\beta=.04$. We then estimated a measurement model comprising of the two personality trait latent constructs. The model showed an acceptable fit, $\chi^{2}(8)=31.57, p<.01, \mathrm{CFI}=.988, \mathrm{SRMR}=.034, \mathrm{RMSEA}=.055$. The agreeableness and neuroticism latent factors were correlated at $r=-.28, p<.01$. Adding age to the model evidenced significant but small age associations with the traits, $\beta=.11, p<$ .01 (agreeableness) and $\beta=-.10, p<.01$ (neuroticism).

Next, we examined the discriminant validity of forgivingness with respect to agreeableness and neuroticism, respectively. A single-factor model for describing the relations among the forgivingness and agreeableness indicators did not fit the data well, $\chi^{2}$ $(13)=390.19, p<.01, \mathrm{CFI}=.700, \mathrm{SRMR}=.111, \mathrm{RMSEA}=.175$. The two-factor model with forgivingness and agreeableness as distinct factors fit the data better, $\chi^{2}(12)=40.24, p<.01$, $\mathrm{CFI}=.978, \mathrm{SRMR}=.031, \mathrm{RMSEA}=.050$. Note that in both models the residual covariance between the items 2 and 3 of the forgivingness measure was freely estimated. The change in difference between the two models was statistically significant, $\Delta \chi^{2}(1)=349.95, p<.01$, revealing the two-factor model to be an improvement in fit over the single-factor model. Next, a single-factor model combining forgivingness and neuroticism indicators was a poor fit to the data, $\chi^{2}(13)=367.89, p<.01, \mathrm{CFI}=.825, \mathrm{SRMR}=.106, \mathrm{RMSEA}=.170$. The two-factor model with separate factors for forgivingness and neuroticism appeared more adequate, $\chi^{2}$ $(12)=59.57, p<.01, \mathrm{CFI}=.977, \mathrm{SRMR}=.045, \mathrm{RMSEA}=.065, \Delta \chi^{2}(1)=308.32, p<.01$. Again, the residual covariance between the items 2 and 3 of the forgivingness measure was freely estimated in both models. 
Eventually, we estimated a measurement model with the three latent constructs forgivingness, agreeableness, and neuroticism. Again, the residual covariance between the items 2 and 3 of the forgivingness measure was freely estimated. This model demonstrated an acceptable fit, $\chi^{2}(31)=127.04, p<.01, \mathrm{CFI}=.965, \mathrm{SRMR}=.044, \mathrm{RMSEA}=.057 . \mathrm{We}$ therefore decided that this model adequately describes the data and exhibits the basic model for the mediation analyses. The correlations between the latent factors were: forgivingness and agreeableness, $r=.38, p<.01$, forgivingness and neuroticism, $r=-.48, p<.01$, and neuroticism and agreeableness, $r=-.34, p<.01$.

\section{Test of the Mediation Hypothesis}

After these preliminary analyses we examined whether the association between age and forgivingness is partially mediated by agreeableness and neuroticism. Thus, we set up a latent variable mediation model as specified in the statistical analyses section. Again, a residual covariance between the forgivingness items 2 and 3 was freely estimated. Due to the fact that the two mediators were interrelated a residual covariance was freely estimated. Moreover, we controlled for gender effects. The model demonstrated an acceptable fit, $\chi^{2}(45)=173.32, p<$ $.01, \mathrm{CFI}=.955, \mathrm{SRMR}=.042, \mathrm{RMSEA}=.055$. The residual correlation between agreeableness and neuroticism was $r=-.35, p<.01$. The unstandardized and standardized estimates for direct, indirect and total effects, as well as the $95 \%$ bootstrap confidence intervals for all effects appear in Table 2. All direct effects were substantial, standardized estimates $>.10$, and significant, $p<.01$; except for the path from age $\rightarrow$ neuroticism, standardized estimate $=-.08, p<.05$. An examination of the indirect effect supports our hypothesis that the effect of age on forgivingness is partially mediated by agreeableness and neuroticism. The total indirect effect was statistically significant, standardized estimate $=.06$, $p<.01$, although the specific indirect effect via agreeableness appeared to be stronger than the indirect effect via neuroticism (see Table 2 and Figure 1). We also reran the mediation 
models separately for each of the two personality traits. Although the estimates, on average, became somewhat stronger, these additional analyses did not lead to different results.

To summarize, the results from Study 1 showed that forgivingness is related to but distinct from agreeableness and neuroticism, respectively. Moreover, the present results support our hypothesis that agreeableness and neuroticism partially mediate the association between age and forgivingness. Study 2 sought to replicate and extend these findings by adding an alternative explanation for age differences in forgivingness, namely transgression occurrences (Steiner et al., in press).

\section{Study 2}

\section{Method}

\section{Participants and Procedure}

Four hundred and fifty-one participants $(56.7 \%$ women $)$ ranging in age from 20 to 83 $(M=52.3$ years, $S D=16.9)$ participated in a large-scale survey. There was a broad range in educational attainment. Of the participants, $7.8 \%$ reported having a basic education (i.e., primary and secondary school) as the highest level of education, $44.5 \%$ had a high school education or equivalent (e.g., vocational school), $24.9 \%$ completed a degree from a technical school, and $22.7 \%$ completing a university degree. Regarding marital status, $32.4 \%$ participants were single, $48.2 \%$ were married, $12.3 \%$ were either separated or divorced, and $7.1 \%$ were widowed.

We used the same sampling procedure including an age-stratified random selection of prospective study participants accomplished by the registration office of the city of Zurich as described for Study 1. From each birth-year age group (1927 to 1987) we included 30 adults with an approximately equal ratio of men and women, resulting in 1,800 prospective

participants. The response rate was $25 \%$, and thus similar to the response rate in Study 1 . All participants were unpaid volunteers. 
To determine the degree of sample selectivity, we compared the initial sample of prospective participants $(N=1,800)$ with the final sample $(N=451)$ with respect to age and gender, as we only have information regarding age and gender of the prospective participants. The mean age in the final sample $(M=52.3, S D=16.9)$ was slightly higher than in the entire sample $(M=50.6, S D=17.0)$. However, in terms of effect sizes this difference is small, $d=$ .10. The gender distribution in the entire sample was $53.0 \%$ women, and only a slightly higher proportion of females participated in the study (56.7\%).

\section{Measures}

The same forgivingness and personality trait measures from Study 1were used. The alpha reliability estimates for the scales were: TTF: $\alpha=.71$, Agreeableness: $\alpha=.67$, Neuroticism: $\alpha=.82$.

Additional potential mediator. The Transgression Occurrences Measure (TOM; McCullough, Emmons, Kilpatrick, \& Mooney, 2003) was used to assess the frequency and intensity of a variety of interpersonal transgressions. Participants indicated how frequently different transgressions have occurred to them in their relationships with other people in the past 12 months using a 4-point Likert type scale ranging from never (0) to often (3). Approximately half of the transgressions were "sins of commission" that would be relatively unambiguous and thus highly visible to a third party (e.g., degraded you in public, damaged something that belonged to you), and approximately half were "sins of omission" (e.g., failed to appreciate you adequately, took advantage of you). Participants also rated the perceived intensity of the experienced transgressions using a 4-point Likert-type scale ranged from not at all (0) to very extremely (3). The alpha reliability estimates for the frequency and intensity subscales were .90 and .92 , respectively (for more information regarding the TOM, see McCullough et al., 2003; Steiner et al., in press).

\section{Results and Discussion}

\section{Test of the Mediation Hypothesis}


Means, standard deviations, and correlations between study variables appear in Table 3. First, the analyses started with a measurement model comprising the three latent constructs: forgivingness, agreeableness, and neuroticism. The residual covariance between the forgivingness items 2 and 3 was freely estimated (see results section Study 1). This model demonstrated an acceptable fit, $\chi^{2}(31)=107.14, p<.01, \mathrm{CFI}=.937, \mathrm{SRMR}=.059$, RMSEA $=.075$. Following the modification indices, additionally the residual covariance between the two other forgivingness items 1 and 4 was freely estimated. This resulted in a better model fit, $\chi^{2}(30)=96.78, p<.01, \mathrm{CFI}=.945, \mathrm{SRMR}=.054, \mathrm{RMSEA}=.072$. We thus decided that this model adequately described the data. The correlations between the latent factors were: forgivingness and agreeableness, $r=.41, p<.01$, forgivingness and neuroticism, $r=-.48, p<$ .01 , and neuroticism and agreeableness, $r=-.22, p<.01$. Adding age to the model evidenced significant age associations with the latent trait factors, $\beta=.27, p<.01$ (forgivingness), $\beta=$ $.20, p<.01$ (agreeableness) and $\beta=-.15, p<.01$ (neuroticism).

Second, to replicate the results from Study 1 we set up the similar structural mediation model with agreeableness and neuroticism as mediators. Again, a residual covariance between the forgivingness items 2 and 3 and 1 and 4, respectively, was freely estimated. Due to the fact that the two mediators were interrelated a residual covariance was freely estimated. Moreover, we controlled for gender effects. The model demonstrated an acceptable fit, $\chi^{2}(44)$ $=121.09, p<.01, \mathrm{CFI}=.940, \mathrm{SRMR}=.051, \mathrm{RMSEA}=.064$. The residual correlation between agreeableness and neuroticism was $r=-.21, p<.01$. The unstandardized and standardized estimates for direct, indirect and total effects, as well as the $95 \%$ bootstrap confidence intervals for all effects are presented in Table 4. The present results replicated the findings from Study 1 showing that the effect of age on forgivingness is partially mediated by agreeableness and neuroticism. The total indirect effect was statistically significant, standardized estimate $=.13, p<.01$. As in Study 1 , the specific indirect effect via agreeableness seems to be slightly stronger than via neuroticism (see Table 4 and Figure 1). 


\section{Extension of the Multi-Mediator Model}

To extend the present results we added the latent mediator transgression occurrences to our multi-mediator model. The aim was to simultaneously investigate agreeableness, neuroticism and transgression occurrences for the association between age and forgivingness. The additional latent mediator consisted of the two manifest indicators transgression frequency and perceived transgression intensity. Moreover, the residual correlations among the three mediators were freely estimated. The model fit was $\chi^{2}(62)=178.44, p<.01, \mathrm{CFI}=$ $.935, \mathrm{SRMR}=.051, \mathrm{RMSEA}=.066$. The residual correlations were: agreeableness and neuroticism, $r=-.21, p<.01$, transgression occurrences and agreeableness, $r=-.10, p<.10$, transgression occurrences and neuroticism, $r=.39, p<.01$. The unstandardized and standardized estimates and the $95 \%$ bootstrap confidence intervals for all effects are presented in Table 5. Adding the latent mediator transgression occurrences to the mediation model reduced the direct effect from age to forgivingness, standardized estimate $=.11, p<.07$. The results of the specific indirect effects support the mediating hypothesis for agreeableness and neuroticism. However, transgression occurrences failed to be a significant mediator when agreeableness and neuroticism are simultaneously taken into account. The total indirect effect was statistically significant, standardized estimate $=.15, p<.01$ (see Figure 2).

To summarize, the results from Study 2 replicated the findings from Study 1 and thus support our hypothesis that agreeableness and neuroticism partially mediate the association between age and forgivingness. Adding transgression occurrences as an additional mediator into the model did not substantially change the results. The present findings add to the literature by showing that agreeableness and neuroticism explain the association between age and forgivingness over and above the mediating effect of transgression occurrences.

Conversely, transgression occurrences did not appear to mediate the relationship of age with forgivingness when agreeableness and neuroticism were simultaneously taken into account.

\section{Discussion}


The objective of the present investigation was to clarify the role of age-related differences in agreeableness and neuroticism as the cause of cross-sectional age differences in forgivingness. We tested the hypothesis that agreeableness and neuroticism partially mediate the association between age and forgivingness. The results from two studies supported our hypothesis. Four results stand out. First, in line with theory and previous research (Allemand, 2008; Mullet et al., 1998; Toussaint et al., 2001; Steiner et al., in press), we found age differences in forgivingness, showing that older adults tended to be more forgiving than middle-aged and younger adults. In both studies, the correlations between age and forgivingness were similar or even larger in magnitude as compared to correlations between age and the Big Five personality traits (cf. Roberts et al., 2008). It is important to note that we modeled the associations between age and the constructs of interest on the latent level by means of SEM, that is, estimates were uncontaminated by measurement error, and thus reflect precise estimations of the associations.

Second, in line with previous research on age differences and age-related changes in personality traits across the lifespan (Allemand, Zimprich, \& Martin, 2008; Donnellan \& Lucas, 2008; Roberts et al., 2006; Soto et al., 2011) we found significant age differences for agreeableness and neuroticism, implying that older adults tended to be more agreeable and less neurotic than middle-aged and older adults. Likewise, we found significant associations between the two personality traits and the tendency to forgive, indicating that agreeable and emotional stable people tended to be more willing to forgive others than less agreeable and neurotic people (Berry et al., 2005; Brown, 2003; Fehr et al., 2010). The results are consistent with research showing that individuals who score high in agreeableness demonstrate less negative responses to transgressions and are more empathic than less agreeable individuals (McCullough \& Hoyt, 2002). Agreeable people also tend to use more cooperative and integrative problem solving strategies, whereas less agreeable people often chose power assertions or disengagement in interpersonal conflict situations (Graziano, Jensen-Campbell, 
$\&$ Hair, 1996). The results are also consistent with research showing that neuroticism influences people in stressful situations and often leads to ineffective coping efforts (Bolger, 1990). Individuals who score high in neuroticism demonstrate more negative emotional reactions and have a stronger tendency to ruminate over negative life events in stressful situations (Allemand, Job et al., 2008; McCullough \& Hoyt, 2002). Likewise, individual differences in dispositional anger and rumination inhibit the tendency to forgive others (Berry et al., 2005; McCullough et al., 2001). Although in the present investigation forgivingness, agreeableness and neuroticism, respectively, shared considerable amounts of common variance, our analyses have demonstrated that those constructs are related but clearly distinct.

Third, in support of our hypothesis, we found that agreeableness and neuroticism partially mediate the association between age and forgivingness. Older adults were, on average, more willing to forgive others than middle-aged and younger adults because they were also more agreeable and less neurotic. Due to the dispositional character of forgivingness the present results might be discussed in light of some principles of personality trait development. For example, the maturity principle assumes that people become more emotional stable, agreeable, self-controlled, and responsible with age as a consequence of maturity (Roberts \& Wood, 2006). The social investment principle (e.g., Lodi-Smith \& Roberts, 2007) supposes that personality trait development is largely the result of experiences of age-graded social roles. These social roles include a set of expectations from the society and the self that promote being more agreeable, conscientious, and less neurotic. Alternative explanations refer to more context-related issues. For example, across the entire lifespan people are confronted with different life experiences including interpersonal conflicts and transgressions and have to learn to deal with (cf. Baltes et al., 2006). As a consequence of increasing life experience and expertise, individuals may become more experienced, confident, and emotional stable, which might increase the tendency to forgive. It is also 
possible that older adults are treated differently and more kindly by others than middle-aged and younger adults (Fingerman \& Pitzer, 2007).

Fourth, in the present investigation we also tested the mediating role of agreeableness and neuroticism independently of individual differences in self-reported transgression occurrences. Recently, Steiner et al. (in press) demonstrated that older adults experienced fewer transgressions and perceived transgressions as less intense as compared to younger adults. Here, we found that transgression occurrences partially explained age differences in forgivingness, but we also found that agreeableness and neuroticism partially explained the association between age and forgivingness over and above the effect of transgression occurrences. Put differently, we provided empirical evidence that agreeableness and neuroticism accounted for greater variance in age differences in dispositional forgivingness than frequency and intensity of transgression occurrences. It is possible that the opposite is true for age differences in forgiveness of a single transgressor by a single victim. Future studies should test this idea.

Some limitations of the present investigation have to be noted. First, the cross-sectional nature of the studies demands caution in the interpretation of the data. It is not clear whether the findings truly represent a developmental process or whether they simply reflect a cohort effect. However, the comparison of findings from cross-sectional and longitudinal studies can provide insight. As previously noted, our results with respect to age differences in agreeableness and neuroticism are comparable to the findings of previous cross-sectional (Donnellan \& Lucas, 2008; Soto et al., 2011) and longitudinal studies (Roberts et al., 2006; Terracciano et al., 2005). Also, similar age differences were found with respect to agreeableness and neuroticism in a variety of cultures (McCrae et al., 1999). However, longitudinal studies are specifically needed to confirm that age differences in forgivingness are indeed a result of developmental trends. Moreover, although it is not possible to draw conclusions about the direction of the effects given the cross-sectional nature of the data 
examined here, based on our theoretical rationale it seems plausible that the two global traits agreeableness and neuroticism are antecedents of the situational trait forgivingness. Indeed, studies have shown that personality traits predict forgiveness (e.g., Maltby et al., 2008). However, future longitudinal studies with a focus on explaining adult personality development may test the alternative hypothesis that forgiveness as a complex process of change (McCullough, Luna, Berry, Tabak, \& Bono, 2010) is related to individual differences in change in agreeableness and emotional stability.

Second, findings were based on self-reports. This method leaves open the possibility that participants responded on the basis of their ideas about what would be socially desirable, as opposed to what they would actually do. Future studies should use an experimental setting with observer reports and behavioral measures as well. However, research has demonstrated that self-report measures of the tendency to forgive predict actual behavior. For example, Thompson et al. (2005) demonstrated that individuals who score high in forgivingness preferred to listen longer to forgiving statements and recalled them better. Another limitation involves the assessment of transgression frequency and intensity based on retrospective selfreports. It is possible that age differences in transgression occurrences might be driven by perceptual changes or by memory effects. For examples, research on memory for positive, neutral, and negative stimuli has shown that older adults remember the stimuli as less negative and sometimes even as more positive than younger adults (Charles \& Carstensen, 2010). Moreover, it is possible that individuals with high levels in forgivingness show differential perceptual and memory effects as compared to people with low levels in forgivingness. Future experimental research should take possible perceptual and memory effects into account. Another possibility is to use daily diary data to assess transgression occurrences.

To conclude, very few studies have empirically tested potential explications for age differences in forgivingness. The present study was designed to clarify the role of 
agreeableness and neuroticism as explanatory accounts. We selected two of the most consistent dispositional correlates of forgivingness and conducted two studies with large and representative samples of adults with a broad age range. We found empirical evidence for our hypothesis that agreeableness and neuroticism partially mediate the association between age and forgivingness. Put differently, older adults are more willing to forgive others, partly because they are more agreeable and less neurotic than younger adults. A forgiving personality facilitates maintaining and restoring social relationships across the lifespan into old age. The present findings are important, because they show that regardless of the causal direction underlying the mediation effect, age differences in forgivingness are related to age differences in agreeableness and neuroticism. The present findings are also important, because they clearly point to positive aspects of aging. Aging is not only a matter of losses, but also of gains, both for the individual and for his/her social relationships. The present findings are also important from an applied perspective and have practical implication for forgiveness interventions with different age groups such as younger versus older adults. Elsewhere we argued that explicitly taking age-specific issues such as age differences or agerelated changes in agreeableness, neuroticism and other individual differences into account in interventions might strengthen the benefits of interventions that help people to deal with interpersonal conflicts and transgressions (Allemand \& Steiner, in press). 


\section{Author Notes}

This publication is based on data from a research project funded by a grant (NFP 58;

No. 4058-115787) from the Swiss National Science Foundation (Study 1) and from a research project funded by a research grant (FAN) from the Zürcher Universitätsverein of the

University of Zurich (Study 2). We gratefully acknowledge the help of Petra Kleeb and Catherine Mott with data collection in Study 2.

The first two authors contributed equally to this paper. 


\section{References}

Allemand, M. (2008). Age differences in forgivingness: The role of future time perspective. Journal of Research in Personality, 42, 1137-1147.

Allemand, M., Job, V., Christen, S., \& Keller, M. (2008). Forgivingness and action orientation. Personality and Individual Differences, 45, 762-766.

Allemand, M., \& Steiner, M. (in press). Situation-specific forgiveness and dispositional forgiveness: A lifespan perspective. In E. Kahls \& J. Maes (Eds.), Justice psychology and conflict (pp. xx-xx). New York: Springer.

Allemand, M., \& Steiner, M. (2010). Verzeihen und Selbstverzeihen über die Lebensspanne: Gegenwärtiger Forschungsstand und Forschungsperspektiven. [Forgiveness and selfforgiveness across the lifespan: Current status and future directions]. Zeitschrift für Entwicklungspsychologie und Pädagogische Psychologie, 42, 63-78.

Allemand, M., Zimprich, D., \& Hendriks, A. A. J. (2008). Age differences in five personality domains across the life span. Developmental Psychology, 44, 758-770.

Allemand, M., Zimprich, D., \& Martin, M. (2008). Long-term correlated change in personality traits in old age. Psychology and Aging, 23, 545-557.

Asendorpf, J. B., \& Wilpers, S. (1998). Personality effects on social relationship. Journal of Personality and Social Psychology, 74, 1531-1544.

Ashton, M. C., Paunonen, S. V., Helmes, E., \& Jackson, D. N. (1998). Kin altruism, reciprocal altruism, and the Big Five personality factors. Evolution and Human Behavior, 19, 243-255.

Baltes, P. B., Lindenberger, U., \& Staudinger, U. M. (2006). Life span theory in developmental psychology. In W. Damon \& R. M. Lerner (Eds.), Handbook of child psychology: Vol. 1. Theoretical models of human development (6th ed., pp. 569-664). New York: Wiley. 
Berry, J. W., Worthington, E. L., Jr., O’Connor, L. E., \& Wade, N. E. (2005). Forgivingness, vengeful rumination, and affective traits. Journal of Personality, 73, 183-225.

Berry, J. W., Worthington, E. L., Jr., Parrott, L., O’Connor, L. E., \& Wade, N. E. (2001). Dispositional forgivingness: Development and construct validity of the transgression narrative test of forgivingness (TNTF). Personality and Social Psychology Bulletin, 27, 1277-1290.

Bolger, N. (1990). Coping as a personality process: A prospective study. Journal of Personality and Social Psychology, 59, 525-537.

Bono, G., \& McCullough, M. E. (2004). Religion, forgiveness, and adjustment in older adults. In K. W. Schaie, N. Krause \& A. Booth (Eds.), Religious influences on health and wellbeing in the elderly (pp. 163-186). New York: Springer.

Brown, R. P. (2003). Measuring individual differences in the tendency to forgive: Construct validity and links with depression. Personality and Social Psychology Bulletin, 29, 759771.

Brown, R. P., \& Phillips, A. (2005). Letting bygones be bygones: further evidence for the validity of the Tendency to Forgive scale. Personality and Individual Differences, 38 , 627-638.

Browne, M. W., \& Cudeck, R. (1993). Alternative ways of assessing model fit. In K. A. Bollen \& J. S. Long (Eds.), Testing Structural Equation Models (pp. 136-162). Beverly Hills, CA: Sage.

Carstensen, L. L., Isaacowitz, D. M., \& Charles, S. T. (1999). Taking time seriously: A theory of socioemotional selectivity. American Psychologist, 54, 165-181.

Charles, S., \& Carstensen, L. L. (2010). Social and emotional aging. Annual Review of Psychology, 61, 383-409.

Cheng, S.-T., \& Yim, Y.-K. (2008). Age differences in forgiveness: The role of future time perspective. Psychology and Aging, 23, 676-680. 
Derryberry, D., \& Reed, M. A. (1994). Temperament and attention: Orienting toward and away from positive and negative signals. Journal of Personality and Social Psychology, $66,1128-1139$.

Donnellan, M. B., \& Lucas, R. E. (2008). Age differences in the Big Five across the life span: Evidence from two national samples. Psychology and Aging, 23, 558-566.

Enright, R. D., Gassin, E. A., \& Wu, C. (1992). Forgiveness: A developmental view. Journal of Moral Development, 21, 99-114.

Fehr, R., Gelfand, M. J., \& Nag, M. (in press). The road to forgiveness: A meta-analytic synthesis of its situational and dispositional correlates. Psychological Bulletin.

Fingerman, K. L., \& Pitzer, L. M. (2007). Socialization in old age. In P. D. Hastings \& J. E. Grusec (Eds.), Handbook of socialization: Theory and reserach (pp. 232-255). New York: Guilford.

Funder, D. C. (1991). Global traits: A neo-Allportian approach to personality. Psychological Science, 2, 31-39.

Girard, M., \& Mullet, E. (1997). Propensity to forgive in adolescents, young adults, older adults, and elderly people. Journal of Adult Development, 4, 209-220.

Graziano, W. G., Jensen-Campell, L. A., \& Hair, E. C. (1996). Perceiving interpersonal conflict and reacting to it: The case for agreeableness. Journal of Personality and Social Psychology, 70, 820-835.

Hill, P., \& Allemand, M. (2010). Forgivingness and adult patterns of individual differences in environmental mastery and personal growth. Journal of Research in Personality, 44, 245-250.

Hu, L., \& Bentler, P. M. (1998). Fit indices in covariance structure modeling: sensitivity to underparameterized model misspecification. Psychological Methods, 3, 424-453.

Idler, E. (2006). Religion and aging. In R. H. Binstock \& L. K. George (Eds.), Handbook of Aging and the Social Sciences (6th ed., pp. 277-300). San Diego: Elsevier. 
John, O. P., Donahue, E. M., \& Kentle, R. L. (1991). The Big Five Inventory-Versions 4a and 54. Berkeley, CA: University of California, Berkeley, Institute of Personality and Social Research.

John, O. P., Naumann, L. P., \& Soto, C. J. (2008). Paradigm shift to the integrative Big-Five trait taxonomy: History, measurement, and conceptual issues. In O. P. John, R. W. Robins, \& L. A. Pervin (Eds.), Handbook of personality: Theory and research (3rd ed., pp. 114-158). New York, NY: Guilford Press.

John, O. P., \& Srivastava, S. (1999). The Big Five trait taxonomy: History, measurement, and theoretical perspectives. In L. A. Pervin, \& O. P. John (Eds.), Handbook of personality: Theory and research (2nd ed., pp. 102-138). New York: Guilford.

Krause, N., \& Ellison, C. G. (2003). Forgiveness by God, forgiveness by others, and psychological well-being in late life. Journal for the Scientific Study of Religion, 42, 7793.

Lawler-Row, K. A., \& Piferi, R. L. (2006). The forgiving personality: Describing a life welllived? Personality and Individual Differences, 41, 1009-1020.

Little, T. D., Cunningham, W. A., Shahar, G., \& Widaman, K. F. (2002). To parcel or not to parcel: Exploring the question, weighing the merits. Structural Equation Modeling, 9, 151-173.

Lodi-Smith, J. L., \& Roberts, B. W. (2007). Social investment and personality: A metaanalysis of the relationship of personality traits to investment in work, family, religion, and volunteerism. Personality and Social Psychology Review, 11, 68-86.

MacKinnon, D. P. (2008). Introduction to statistical mediation analysis. Mahwah, NJ: Lawrence Erlbaum and Associates.

MacKinnon, D. P., Lockwood, C. M., Hoffman, J. M., West, S. G., \& Sheets, V. (2002). A comparison of methods to test mediation and other intervening variable effects. Psychological Methods, 7, 83-104. 
Maltby, J., Wood, A., Day, L., Kon, T. W. H, Colley, A., \& Linley, P. A. (2008). Personality predictors of levels of forgiveness two and a half years after the transgression. Journal of Research in Personality, 42, 1088-1094.

McCullough, M. E., Bellah, C. G., Kilpatrick, S. D., \& Johnson, J. L. (2001). Vengelfulness: Relationships with forgiveness, rumination, well-being, and the Big Five. Personality and Social Psychology Bulletin, 27, 601-610.

McCullough, M. E., Emmons, R. A., Kilpatrick, S. D., \& Mooney, L. (2003). Narcissists as „victims“: The role of narcissism in the perception of transgressions. Personality and Social Psychology Bulletin, 29, 885-893.

McCullough, M. E., \& Hoyt, W. T. (2002). Transgression-related motivational dispositions: Personality substrates of forgiveness and their links to the Big Five. Personality and Social Psychology Bulletin, 28, 1556-1573.

McCullough, M. E., Luna, L. R., Berry, J. W., Tabak, B. A., \& Bono, G. (2010). On the form and function of forgiving: Modeling the time-forgiveness relationship and testing the valuable relationships hypothesis. Emotion, 10, 358-376.

McCrae, R. R., Costa, P. T., Jr., Ostendorf, F., Angleitner, A., Hrebickova, M., Avia, M. D., et al. (2000). Nature over nurture: Temperament, personality, and life span development. Journal of Personality and Social Psychology, 78, 173-186.

Miller, A. J., Worthington, E. L., Jr., \& McDaniel, M. A. (2008). Forgiveness and gender: A meta-analytic review and research agenda. Journal of Social and Clinical Psychology, $27,843-876$

Mullet, E., Barros, J., Frongia, L., Usaï, V., Neto, F., \& Rivière Shafighi, S. (2003). Religious involvement and the forgiving personality. Journal of Personality, 71, 1-19.

Mullet, E., \& Girard, M. (2000). Developmental and cognitive points of view on forgiveness. In M. E. McCullough, K. I. Pargament, \& C. E. Thoresen (Eds.), Forgiveness: Theory, research, and practice (pp. 111-132). New York: Guilford. 
Mullet, E., Houdbine, A., Laumonier, S., \& Girard, M. (1998). „Forgivingness“: Factor structure in a sample of young, middle-aged, and elderly adults. European Psychologist, 3, 289-297.

Mullet, E., Neto, F., \& Rivière, S. (2005). Personality and its effects on resentment, revenge, forgiveness, and self-forgiveness. In E. L. Worthington, Jr. (Ed.), Handbook of Forgiveness (pp. 159-182). New York: Routledge.

Preacher, K. J., \& Hayes, A. F. (2008). Asymptotic and resampling strategies for assessing and comparing indirect effects in multiple mediator models. Behavior Research Methods, 40, 879-891.

Rammstedt, B., \& John, O. P. (2005). Kurzversion des Big Five Inventory (BFI-K): Entwicklung und Validierung eines ökonomischen Inventars zur Erfassung der fünf Faktoren der Persönlichkeit. [Short version of the Big Five Inventory (BFI-K): Development and validation of an economic inventory for assessment of the five factors of personality]. Diagnostica, 51, 195-206.

Roberts, B. W., \& Pomerantz, E. M. (2004). On traits, situations, and their integration: A developmental perspective. Personality and Social Psychology Review, 8, 402-416.

Roberts, B. W., Walton, K. E., \& Viechtbauer, W. (2006). Patterns of mean-level change in personality traits across the life course: A meta-analysis of longitudinal studies. Psychological Bulletin, 132, 1-25.

Roberts, B. W., \& Wood, D. (2006). Personality development in the context of the neosocioanalytic model of personality. In D. K. Mroczek, \& T. D. Little (Eds.), Handbook of personality development (pp. 11-39). Mahwah, NJ: Lawrence Erlbaum.

Roberts, B. W., Wood, D., \& Caspi, A. (2008). The development of personality traits in adulthood. In O. P. John, R. W. Robins, \& L. A. Pervin (Eds.), Handbook of personality: Theory and research (3th ed., pp. 375-398). New York: Guilford. 
Romero, C., \& Mitchell, D. B. (2008). Forgiveness of interpersonal offenses in younger and older roman catholic women. Journal of Adult Development, 15, 55-61.

Rosenberg, E. L (1998). Levels of analysis and the organization of affect. Review of General Psychology, 2, 247-270.

Soto, C. J., John, O. P., Gosling, S. D., \& Potter, J. (2011). Age differences in personality traits from 10 to 65 . Big-Five domains and facets in a large cross-sectional sample. Journal of Personality and Social Psychology, 100, 330-348.

Srivastava, S. S., John, O. P., Gosling, S. D., \& Potter, J. (2003). Development of personality in early and middle adulthood: Set like plaster or persistent change? Journal of Personality and Social Psychology, 84, 1041-1053.

Steiner, M., Allemand, M., \& McCullough, M. E. (in press). Age differences in forgivingness: The role of transgression frequency and intensity. Journal of Research in Personality. Subkoviak, M. J., Enright, R. D., Wu, C.-R., Gassin, E. A., Freedman, S., Olson, L. M., \& Sarinopoulos, I. (1995). Measuring interpersonal forgiveness in late adolescence and middle adulthood. Journal of Adolescence, 18, 641-655.

Terracciano, A., McCrae, R. R., Brant, L. J., \& Costa, P. T., Jr. (2005). Hierarchical linear modeling analyses of the NEO-PI-R scales in the Baltimore Longitudinal Study of Aging. Psychology and Aging, 20, 493-506.

Tobin, R. M., Graziano, W. G., Vanman, E. J., \& Tassinary, L. G. (2000). Personality, emotional experience, and efforts to control emotions. Journal of Personality and Social Psychology, 79, 656-669.

Thompson, L. Y., Snyder, C. R., Hoffman, L., Michael, S. T., Rasmussen, H. N., Billings, L. S., Heinze, L., Neufeld, J. E., Shorey, H. S., Roberts, J. C., \& Roberts, D. E. (2005). Dispositional forgiveness of self, others, and situations. Journal of Personality, 73, 313359. 
Toussaint, L. L., Williams, D. R., Musick, M. A., \& Everson, S. A. (2001). Forgiveness and health: Age differences in a U.S. probability sample. Journal of Adult Development, 8, 249-257.

Williams, J., \& MacKinnon, D. P. (2008). Resampling and distribution of the product methods for testing indirect effects in complex models. Structural Equation Modeling, $15,23-51$.

Zimprich, D., Martin, M., Kliegel, M., Dellenbach, M., Rast, P., \& Zeintl, M. (2008).

Cognitive abilities in old age: Results from the Zurich Longitudinal Study on Cognitive Aging. Swiss Journal of Psychology, 67, 177-195. 
Table 1

Means, Standard Deviations, and Correlations Between Study Variables in Study 1

\begin{tabular}{lcccc}
\hline Variable & 1 & 2 & 3 & 4 \\
\hline 1. Age & - & - & & \\
2. Forgivingness & $.22^{*}$ & $.36^{*}$ & - & \\
3. Agreeableness & $.15^{*}$ & $-.40^{*}$ & $-.34^{*}$ & - \\
4. Neuroticism & $-.09^{*}$ & $1-7$ & $1-5$ & $1-5$ \\
Possible range & $19-84$ & 3.82 & 3.64 & 2.64 \\
$M$ & 52.40 & 1.13 & 0.47 & 0.68 \\
$S D$ & 17.65 & & &
\end{tabular}

Note. $N=962$.

$* p<.01$. 
Table 2

Test of Mediation Predicting Forgivingness From Age, With Agreeableness and Neuroticism as Mediators, and Controlled for Gender

\begin{tabular}{|c|c|c|c|c|}
\hline Effects & $\begin{array}{c}\text { Unstandardized } \\
\text { estimate }\end{array}$ & S.E. & $95 \% \mathrm{CI}$ & $\begin{array}{c}\text { Standardized } \\
\text { estimate }\end{array}$ \\
\hline Direct effects & & & $\begin{array}{c}\text { Unstandardized } \\
\text { estimates }\end{array}$ & \\
\hline Age $\rightarrow$ forgivingness & 0.012 & 0.002 & $0.008 ; 0.017$ & $0.195^{* *}$ \\
\hline Age $\rightarrow$ agreeableness & 0.011 & 0.003 & $0.005 ; 0.017$ & $0.151^{* *}$ \\
\hline Age $\rightarrow$ neuroticism & -0.008 & 0.004 & $-0.016 ; 0.000$ & $-0.076^{*}$ \\
\hline Agreeableness $\rightarrow$ forgivingness & 0.194 & 0.048 & $0.103 ; 0.291$ & $0.228^{* *}$ \\
\hline Neuroticism $\rightarrow$ forgivingness & -0.224 & 0.035 & $-0.291 ;-0.156$ & $-0.380 * *$ \\
\hline Specific indirect effects & & & $\begin{array}{l}\text { Standardized } \\
\text { estimates }^{\mathrm{a}}\end{array}$ & \\
\hline Age $\rightarrow$ agreeableness $\rightarrow$ forgivingness & 0.002 & 0.001 & $0.013 ; 0.062$ & $0.034 * *$ \\
\hline Age $\rightarrow$ neuroticism $\rightarrow$ forgivingness & 0.002 & 0.001 & $0.002 ; 0.058$ & $0.029 *$ \\
\hline \multicolumn{5}{|l|}{ Total effects } \\
\hline Total: Age $\rightarrow$ forgivingness & 0.016 & 0.002 & $0.183 ; 0.332$ & $0.258^{* *}$ \\
\hline Total indirect: Age $\rightarrow$ forgivingness & 0.004 & 0.001 & $0.022 ; 0.105$ & $0.063 * *$ \\
\hline
\end{tabular}

Notes. $N=962$; asymmetric percentile $95 \%$ confidence intervals (CI) were estimated for all effects using 5,000 bootstrap samples; ${ }^{a}$ an effect is statistically significant if its confidence interval does not include zero; ${ }^{*} p<.05,{ }^{*} p<.01$. 
Table 3

Means, Standard Deviations, and Correlations Between Study Variables in Study 2

\begin{tabular}{lcccccc}
\hline Variable & 1 & 2 & 3 & 4 & 5 & 6 \\
\hline 1. Age & - & & & & & \\
2. Forgivingness & $.22^{* *}$ & - & & & & \\
3. Agreeableness & $.24 * *$ & $.25^{*}$ & - & & & \\
4. Neuroticism & $-.10^{*}$ & $-.38^{* *}$ & $-.27^{*}$ & - & & \\
5. Transgression frequency & $-.19^{* *}$ & $-.20^{* *}$ & $-.19^{* *}$ & $-.36^{* *}$ & - & - \\
6. Transgression intensity & $-.30^{* *}$ & $-.25^{*}$ & $-.18^{* *}$ & $-.33^{* *}$ & $-.76^{* *}$ & - \\
Possible range & $20-83$ & $1-7$ & $1-5$ & $1-5$ & $0-3$ & $0-3$ \\
$M$ & 52.26 & 3.94 & 3.68 & 2.75 & 0.62 & 0.77 \\
$S D$ & 16.88 & 1.17 & 0.47 & 0.67 & 0.42 & 0.55 \\
\hline
\end{tabular}

Note. $N=451$.

$* p<.05, * * p<.01$. 
Table 4

Test of Mediation Predicting Forgivingness From Age, With Agreeableness and Neuroticism as Mediators, and Controlled for Gender

\begin{tabular}{|c|c|c|c|c|}
\hline Effects & $\begin{array}{c}\text { Unstandardized } \\
\text { estimate }\end{array}$ & S.E. & $95 \% \mathrm{CI}$ & $\begin{array}{c}\text { Standardized } \\
\text { estimate }\end{array}$ \\
\hline Direct effects & & & $\begin{array}{c}\text { Unstandardized } \\
\text { estimates }\end{array}$ & \\
\hline Age $\rightarrow$ forgivingness & 0.008 & 0.004 & $0.001 ; 0.016$ & $0.131^{*}$ \\
\hline Age $\rightarrow$ agreeableness & 0.018 & 0.005 & $0.009 ; 0.028$ & $0.226^{* *}$ \\
\hline Age $\rightarrow$ neuroticism & -0.015 & 0.006 & $-0.027 ;-0.004$ & $-0.138 * *$ \\
\hline Agreeableness $\rightarrow$ forgivingness & 0.250 & 0.070 & $0.105 ; 0.383$ & $0.315^{* *}$ \\
\hline Neuroticism $\rightarrow$ forgivingness & -0.225 & 0.047 & $-0.316 ;-0.128$ & $0.395 * *$ \\
\hline Specific indirect effects & & & $\begin{array}{l}\text { Standardized } \\
\text { estimates }^{\mathrm{a}}\end{array}$ & \\
\hline Age $\rightarrow$ agreeableness $\rightarrow$ forgivingness & 0.005 & 0.002 & $0.024 ; 0.129$ & $0.071 * *$ \\
\hline Age $\rightarrow$ neuroticism $\rightarrow$ forgivingness & 0.003 & 0.002 & $0.012 ; 0.105$ & $0.054^{*}$ \\
\hline \multicolumn{5}{|l|}{ Total effects } \\
\hline Total: Age $\rightarrow$ forgivingness & 0.016 & 0.004 & $0.139 ; 0.369$ & $0.257 * *$ \\
\hline Total indirect: Age $\rightarrow$ forgivingness & 0.008 & 0.002 & $0.062 ; 0.195$ & $0.126^{* *}$ \\
\hline
\end{tabular}

Notes. $N=451$; asymmetric percentile $95 \%$ confidence intervals (CI) were estimated for all effects using 5,000 bootstrap samples; ${ }^{\mathrm{a}}$ an effect is statistically significant if its confidence interval does not include zero; ${ }^{*} p<.05,{ }^{*} p<.01$. 
Table 5

Test of Mediation Predicting Forgivingness From Age, With Agreeableness, Neuroticism, and Transgression Occurrences as Mediators, and Controlled for Gender

\begin{tabular}{|c|c|c|c|c|}
\hline Effects & $\begin{array}{l}\text { Unstandardized } \\
\text { estimate }\end{array}$ & S.E. & $95 \% \mathrm{CI}$ & $\begin{array}{l}\text { Standardized } \\
\text { estimate }\end{array}$ \\
\hline Direct effects & & & $\begin{array}{c}\text { Unstandardized } \\
\text { estimates }\end{array}$ & \\
\hline Age $\rightarrow$ forgivingness & 0.007 & 0.004 & $0.000 ; 0.014$ & $0.111^{*}$ \\
\hline Age $\rightarrow$ agreeableness & 0.018 & 0.005 & $0.009 ; 0.028$ & $0.226 * *$ \\
\hline Age $\rightarrow$ neuroticism & -0.015 & 0.006 & $-0.027 ;-0.004$ & $-0.137 * *$ \\
\hline Age $\rightarrow$ transgression occurrences & -0.006 & 0.001 & $-0.008 ;-0.004$ & $-0.279 * *$ \\
\hline Agreeableness $\rightarrow$ forgivingness & 0.245 & 0.072 & $0.094 ; 0.383$ & $0.308 * *$ \\
\hline Neuroticism $\rightarrow$ forgivingness & -0.207 & 0.046 & $-0.296 ;-0.117$ & $-0.365 * *$ \\
\hline Transgression occurrences $\rightarrow$ forgivingness & -0.283 & 0.253 & $-0.800 ; 0.202$ & -0.092 \\
\hline Specific indirect effects & & & $\begin{array}{l}\text { Standardized } \\
\text { estimates }^{\text {a }}\end{array}$ & \\
\hline Age $\rightarrow$ agreeableness $\rightarrow$ forgivingness & 0.004 & 0.002 & $0.023 ; 0.128$ & $0.070 * *$ \\
\hline Age $\rightarrow$ neuroticism $\rightarrow$ forgivingness & 0.003 & 0.002 & $0.011 ; 0.099$ & $0.050^{*}$ \\
\hline $\begin{array}{l}\text { Age } \rightarrow \text { transgression occurrences } \rightarrow \\
\text { forgivingness }\end{array}$ & 0.002 & 0.001 & $-0.018 ; 0.074$ & 0.026 \\
\hline
\end{tabular}


Explaining Age Differences in Forgivingness 38

Total effects

Total: Age $\rightarrow$ forgivingness

0.016

0.004

$0.138 ; 0.369$

$0.256 * *$

Total indirect: Age $\rightarrow$ forgivingness

0.009

0.002

$0.073 ; 0.220$

$0.145^{* *}$

Notes. $N=451$; asymmetric percentile $95 \%$ confidence intervals (CI) were estimated for all effects using 5,000 bootstrap samples; ${ }^{\text {a }}$ an effect is statistically significant if its confidence interval does not include zero; $p<.07,{ }^{*} p<.05,{ }^{*} p<.01$. 
Figure Captions

Figure 1. The mediation model includes age as manifest independent variable, agreeableness and neuroticism as latent mediator variables, and forgivingness as latent outcome variable. The standardized estimates from Study 1 (in bold) and Study 2 are shown in this figure. The manifest indicators of the latent variables are not depicted. $* p<.05, * * p<.01$.

Figure 2. The mediation model includes age as manifest independent variable, agreeableness, neuroticism, and transgression occurrences as latent mediator variables, and forgivingness as latent outcome variable. The standardized estimates are shown in this figure. The manifest indicators of the latent variables are not depicted. ${ }^{*} p<.07,{ }^{*} p<.05, * * p<.01$. 